\title{
Synchronous biliary gallstones and colorectal cancer: A single center analysis
}

\author{
NARCIS OCTAVIAN ZARNESCU ${ }^{1,2^{*}}$, EUGENIA CLAUDIA ZARNESCU ${ }^{1,2^{*}}$, IOANA DUMITRASCU $^{2}$, \\ ALEXANDRU CHIRCA ${ }^{1,2}$, NICOLETA SANDA ${ }^{1,2}$, ANDREEA ILIESIU ${ }^{3,4}$ and RADU COSTEA ${ }^{1,2}$ \\ ${ }^{1}$ Department of Surgery, 'Carol Davila' University of Medicine and Pharmacy, 020021 Bucharest; \\ ${ }^{2}$ Second Department of Surgery, University Emergency Hospital, 050098 Bucharest; \\ ${ }^{3}$ Department of Pathology, 'Carol Davila' University of Medicine and Pharmacy, 020021 Bucharest; \\ ${ }^{4}$ Department of Pathology, University Emergency Hospital, 050098 Bucharest, Romania
}

Received October 18,2021; Accepted November 17, 2021

DOI: $10.3892 /$ etm.2021.11061

\begin{abstract}
Gallstones and colorectal cancer (CRC) are two common disorders that may develop simultaneously. In such situations, there is a significant chance of missing one of the conditions due to the primary clinical presentation. Late detection, diagnosis and treatment can be especially problematic in the case of unrecognized CRC. In the present study, the medical charts were retrospectively reviewed for all consecutive patients who were treated in the Second Department of Surgery, University Emergency Hospital Bucharest (Romania) between February 2015 and December 2017 following a diagnosis of CRC and/or biliary stones. There were 203 patients with CRC, 433 with biliary gallstones and 19 patients with both conditions. There were 125 men (61.6\%) in the CRC group and 138 men (31.9\%) in the gallstone group. The average age was $54.1 \pm 15.9$ years in the gallstone group and $66.1 \pm 11.6$ years in the CRC group. Obesity was observed in 96 patients (22.2\%) with gallstones and in 14 (6.9\%) patients in the CRC group. In the CRC group, 80 patients had medical comorbidities (39.4\%), while in the gallstone group 126 patients (29.1\%) had medical comorbidities. Bivariate analysis comparing gallstone only vs. gallstone and $\mathrm{CRC}$ identified age $(\mathrm{P}=0.001)$, male sex $(\mathrm{P}=0.001)$ and thyroid disease $(\mathrm{P}=0.001)$ as significant factors associated with synchronous diagnosis. The multivariable logistic regression of factors predicting CRC in patients with gallstones identified age (OR, 1.06; 95\% CI, 1.023-1.105; $\mathrm{P}=0.002)$ and thyroid diseases $(\mathrm{OR}, 11.15 ; 95 \% \mathrm{CI}$, 2.532-49.06; $\mathrm{P}=0.001)$ as independent factors. There were significant differences regarding the location of the tumor between the
\end{abstract}

Correspondence to: Dr Narcis Octavian Zarnescu, Department of Surgery, 'Carol Davila' University of Medicine and Pharmacy, 169 Splaiul Independentei, 020021 Bucharest, Romania

E-mail: narcis.zarnescu@umfcd.ro

${ }^{*}$ Contributed equally

Key words: colorectal cancer, right-sided colon cancer, gallstones, synchronous, epidemiology, surgery, comorbidity
CRC-only group and the gallstone and $\mathrm{CRC}$ group $(\mathrm{P}=0.001)$ : Rectum (39.7 vs. $5.3 \%$ ), left colon (26.6 vs. $21.1 \%$ ), transverse colon (13 vs. $26.3 \%)$ and right colon (20.7 vs. $47.4 \%)$. The study concluded that, in patients with gallstones, age and thyroid conditions were significantly associated with CRC. Patients with a synchronous diagnosis of gallstones and CRC had significantly more right-sided CRC compared with regular CRC.

\section{Introduction}

Colorectal cancer (CRC) is the third most common cancer type, accounting for $\sim 10 \%$ of all cancers (1). CRC represents the fourth most common cause of cancer-associated death worldwide, with 608,000 deaths recorded annually (1). Regardless of recent molecular stratification and refinements to the classification of CRC, prognosis is strongly correlated with the clinical stage of the tumor, and therefore a delayed diagnosis is generally associated with a poor long-term survival (2-7).

Biliary lithiasis is another significant public health problem, affecting $10-15 \%$ of the adult population (8). The diagnosis of biliary lithiasis is usually straightforward due to widely available ultrasound (US) imaging equipment, allowing for the systematic examination of patients presenting with a clinical picture of acute or chronic abdominal pain. However, due to continuous efforts to reduce the costs and the length of hospital stay for patients with gallstones, a more advanced routine preoperative evaluation is avoided (9-11).

Due to its multiple advantages (shorter hospital stay, more comfortable postoperative period and faster return to full activity) compared with the open approach, laparoscopic cholecystectomy (LC) is the standard approach for gallstone treatment, being suitable even for those patients with acute cholecystitis or those with advanced age (12-15). However, it is speculated that the lack of a manual examination may result in certain intra-abdominal pathologies being overlooked (16). Missed diagnoses of a range of digestive cancer types, including $\mathrm{CRC}$, and gastric and pancreatic cancer, have been previously reported in patients with gallstones, leading to delays in the treatment of neoplastic disease (17-19). One consequence of a delayed diagnosis of CRC is the risk of bowel obstruction, which then requires a Hartmann procedure in a number of cases (20). 
The present study reports the three-year experience of the Second Department of Surgery, University Emergency Hospital Bucharest (Romania) with regard to patients diagnosed with gallstones and CRC as separate or simultaneous diagnoses.

\section{Patients and methods}

Patient recruitment. The medical charts and operative records were retrospectively reviewed for all consecutive patients who were treated in the Second Department of Surgery, University Emergency Hospital Bucharest between February 2015 and December 2017 following a diagnosis of CRC and/or biliary stones. This study was approved by the Institutional Review Board of the Emergency University Hospital of Bucharest (Romania). Data for analysis included patient's diagnosis, age, sex, BMI status and presence of medical comorbidities, such as diabetes mellitus, hypertension, thyroid diseases and chronic liver conditions. The clinical status was documented as either emergency or elective.

Patients with CRC were diagnosed electively using colonoscopy and definitive biopsy. For patients with CRC, the tumor location was recorded. The most common complications of CRC were bowel obstruction and rectal bleeding. Cardinal clinical elements of symptomatic gallstone disease included pain in the right upper abdomen, nausea, vomiting, fever and jaundice. An incidental diagnosis of cholelithiasis was attainable during imaging examinations (abdominal US and abdominal computed tomography).

The synchronous diagnosis group for both CRC and biliary stones included patients with a simultaneous diagnosis of both conditions and those patients that had been previously diagnosed and treated within 1 year before the current hospital admission for the other condition. For patients diagnosed with gallstones, colonoscopy was performed selectively depending on the clinical presentation. CRC was an incidental discovery during the exploratory phase after conversion to open cholecystectomy. Within the synchronous group, some patients with symptomatic CRC were diagnosed postoperatively after laparoscopic cholecystectomy.

Statistical analysis. Values are presented as the mean and standard deviation for continuous variables and $\mathrm{n}(\%)$ for categorical data. The analysis was performed using three groups: CRC only, biliary stones only, and synchronous CRC and gallstones. Comparisons were evaluated using the Mann-Whitney $\mathrm{U}$ test or the Kruskal-Wallis test followed by Bonferroni's post hoc test, for continuous variables, and using the $\chi^{2}$ test of Fisher's exact test for categorical variables. Logistic binary regression analysis with backward stepwise selection was used to assess factors associated with CRC in patients diagnosed with gallstones. Potential variables for regression models were selected based on bivariate associations $(\mathrm{P}<0.10)$. A two-sided P-value of $<0.05$ was considered to indicate a statistically significant difference. Statistical analyses were performed using SPSS software package, version 22 (IBM Corp.).

\section{Results}

Clinicopathological variables. There were 433 patients with biliary gallstones and 203 patients with CRC; nineteen patients had both conditions. There were 125 men $(61.6 \%)$ in the colorectal group and 138 men (31.9\%) in the gallstone group. The average age was $54.1 \pm 15.9$ years in the gallstone group and $66.1 \pm 11.6$ in the CRC group. Obesity was observed in 96 patients (22.2\%) with gallstones and 14 (6.9\%) patients in the CRC group. In the CRC group, 80 patients had medical comorbidities, while in the gallstone group, 126 patients $(29.1 \%)$ had medical comorbidities. The tumor location was the ascending colon in 47 patients $(23.2 \%)$, the transverse colon in 29 patients (14.3\%), the descending and sigmoid colon in 53 patients $(26.1 \%)$, and the rectum in 74 patients $(36.5 \%)$. A total of 28 patients $(13.8 \%)$ presented with bowel obstruction.

Comparison of the gallstone-only, CRC-only and synchronous gallstone-CRC groups. Statistical analysis comparing the gallstone only, gallstone synchronous with CRC, and CRC only groups is presented in detail in Table I. A statistical difference was found with regard to sex distribution between the gallstone only group and the gallstone and CRC group (31.4 vs. $42.1 \%$; $\mathrm{P}=0.001$ ), and there was a trend for more male patients in the CRC group compared with that in the gallstone and CRC group (63.6 vs. $42.1 \% ; \mathrm{P}=0.067)$. The mean age was significantly lower $(\mathrm{P}=0.001)$ in the gallstone group $(53.6 \pm 16.0)$ compared with that in the gallstone and CRC group (65.7 \pm 8.1$)$ and the CRC group (66.1 \pm 11.9$)$.

There was no significant difference between the gallstone group and the gallstone and CRC group with regards to obesity, but there were significantly more cases in the gallstone and CRC group compared with the colorectal group $(\mathrm{P}=0.001)$. Thyroid disease appeared more frequently as an associated pathology in the gallstone and CRC group compared with the other two groups $(\mathrm{P}=0.001)$. There were no significant differences between groups regarding the presence of hypertension and liver disease (liver cirrhosis and chronic hepatitis), but there was a trend $(\mathrm{P}=0.096)$ for more cases with diabetes in the gallstone and $\mathrm{CRC}$ group. There was a significant $(\mathrm{P}=0.002)$ location change of the tumor towards the right-sided colon for the association between biliary stones and CRC compared with the CRC group (Table I). Regarding the emergency cases, there were no statistical differences between bowel obstruction prevalence in the CRC only group (14.1\%) and the gallstone and CRC group (10.5\%). Patients with chronic cholecystitis were significantly $(\mathrm{P}=0.001)$ more frequent ( 8 out of 57 patients; $14.0 \%$ ) in the gallstone and CRC group compared with patients with acute cholecystitis (11 out of 376 patients; $2.9 \%$ ).

Riskfactor analysis for CRC in patients with gallstones. Bivariate analysis was performed separately to identify independent factors predicting colorectal cancer in patients with gallstones. The following parameters were founded suitable for further regression analysis: Age $(\mathrm{P}=0.001)$, diabetes mellitus $(\mathrm{P}=0.069)$, hypertension $(\mathrm{P}=0.070)$ and thyroid disease $(\mathrm{P}=0.009)$. The multivariable logistic regression of factors predicting $\mathrm{CRC}$ in patients with gallstones identified aging (OR, 1.06; 95\% CI, 1.023-1.105; $\mathrm{P}=0.002)$ and thyroid diseases (OR, 11.15; 95\% CI, 2.532-49.06; $\mathrm{P}=0.001)$ as independent factors (Table II).

\section{Discussion}

The present study showed that, in patients with gallstones, age and thyroid dysfunction were significantly associated with 
Table I. Analysis of data from the gallstone only, gallstone and CRC, and CRC only groups.

\begin{tabular}{|c|c|c|c|c|}
\hline Characteristic & $\begin{array}{c}\text { Gallstone } \\
\text { only }(n=414)\end{array}$ & $\begin{array}{l}\text { Gallstone and } \\
\text { CRC }(n=19)\end{array}$ & $\begin{array}{l}\text { CRC only } \\
(n=184)\end{array}$ & P-value \\
\hline Sex, n (\%) & & & & $0.001^{\mathrm{a}}$ \\
\hline Female & $284(68.6)$ & $11(57.9)$ & $67(36.4)$ & \\
\hline Male & $130(31.4)$ & $8(42.1)$ & 117 (63.6) & \\
\hline Mean age $\pm S D$, years & $53.6 \pm 16.0$ & $65.7 \pm 8.1$ & $66.1 \pm 11.9$ & $0.001^{\mathrm{a}}$ \\
\hline Year, n $(\%)^{\mathrm{b}}$ & & & & 0.627 \\
\hline 2015 & $146(97.3)$ & $4(2.7)$ & 59 & \\
\hline 2016 & $154(95.1)$ & $8(4.9)$ & 67 & \\
\hline 2017 & $114(94.3)$ & $7(5.7)$ & 58 & \\
\hline Age group in years, $\mathrm{n}(\%)^{\mathrm{b}}$ & & & & $0.001^{\mathrm{a}}$ \\
\hline$<40$ & $91(100.0)$ & $0(0.0)$ & 2 & \\
\hline $40-49$ & $70(98.6)$ & $1(1.4)$ & 17 & \\
\hline $50-59$ & $84(95.5)$ & $4(4.5)$ & 32 & \\
\hline $60-69$ & $105(93.7)$ & $7(6.3)$ & 61 & \\
\hline $70-79$ & $49(87.5)$ & $7(12.5)$ & 43 & \\
\hline$>80$ & $15(100)$ & $0(0.0)$ & 29 & \\
\hline Obesity, n (\%) & $92(22.2)$ & $4(21.1)$ & $10(5.4)$ & $0.001^{\mathrm{a}}$ \\
\hline \multicolumn{5}{|l|}{ Medical comorbidities } \\
\hline Diabetes mellitus & $33(8.0)$ & $4(21.1)$ & $12(6.5)$ & 0.096 \\
\hline Hypertension & $78(18.8)$ & $5(26.3)$ & $40(19.7)$ & 0.118 \\
\hline Thyroid disease & $8(1.9)$ & $3(15.8)$ & $4(2.2)$ & $0.013^{\mathrm{a}}$ \\
\hline Liver disease & $10(2.4)$ & $0(0.0)$ & $5(2.7)$ & 0.692 \\
\hline Tumor location & & & & $0.002^{\mathrm{a}}$ \\
\hline Ascending colon & & $9(47.4)$ & $38(20.7)$ & \\
\hline Transverse colon & & $5(26.3)$ & $24(13.0)$ & \\
\hline Descending and sigmoid colon & & $4(21.1)$ & 49 (26.6) & \\
\hline Rectum & & $1(5.3)$ & $73(39.7)$ & \\
\hline Bowel obstruction & & $2(10.5)$ & $26(14.1)$ & $>0.999$ \\
\hline \multicolumn{5}{|l|}{ Cholecystitis $^{\mathrm{b}}$} \\
\hline Acute cholecystitis & $365(97.1)$ & $11(2.9)$ & & $0.001^{\mathrm{a}}$ \\
\hline Chronic cholecystitis & $49(86.0)$ & $8(14.0)$ & & \\
\hline
\end{tabular}

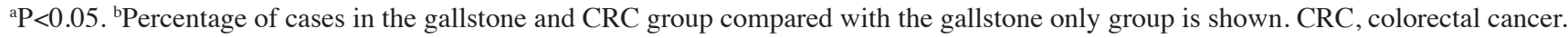

Table II. Multivariable logistic regression of factors predicting colorectal cancer in patients with gallstones.

\begin{tabular}{lrcc}
\hline Variable & OR & $95 \% \mathrm{CI}$ & P-value \\
\hline Thyreopathy & 11.15 & $2.532-49.06$ & 0.001 \\
Age & 1.06 & $1.023-1.105$ & 0.002
\end{tabular}

OR, odds ratio; CI, confidence interval.

CRC. There was a significant location change of the tumor towards the right-sided colon for the association between biliary stones and CRC compared with the CRC group. The male to female ratio for both the gallstone group and the gallstone-CCR group was consistent with a previous report, with the number of female patients being almost double the number of males, but with more male patients in the CCR group (63.6 vs. 36.4\%) (21). It has been documented that the risk of cholelithiasis increases with age, and the present study found that more than half of the patients in the gallstone group were between the ages of 50 and $69(50-59, n=84$; $60-69, n=105)(21,22)$. Obesity is one of the risk factors for the formation of cholesterol gallstones, and is a risk factor that accompanies gallstone complications and cholecystectomy (23). Although the present study found no statistical difference between the gallstone group and the gallstone and CCR group, there were more obese patients in the gallstone and CCR group than in the CCR group (21.1 vs. 5.4\%). To the best of our knowledge, the present study identified, for the first-time, thyroid diseases as significantly associated with gallstones and CRC. Thyroid dysfunction might be a cause of gallstone formation by promoting cholesterol biosynthesis and metabolic pathways (24). In the present study, an association was found between thyroid disease and the patients in the three 
study groups, with thyroid disease appearing more frequently as an associated pathology in the gallstone and CRC group compared with the other two groups.

Increased bile acid secretion (cholic acid and chenodeoxycholic acid) has been shown to be associated with a higher risk of developing CRC $(25,26)$. After a meal, these acids are released and begin their role as fat emulsifiers, forming micelles that are susceptible to the action of pancreatic lipase, only to be deconjugated afterwards by microbial bile salt hydrolase, forming secondary bile acids that are reabsorbed through passive diffusion and active transport in the small intestine (26). Repeated exposure to high concentrations of bile acids appears to be a major factor in CRC carcinogenesis (27). Bile acids promote carcinogenesis through several mechanisms. Induced DNA damage can be attributed to local oxidative damage, and may be a key factor in carcinogenesis, as well as the possibility of induced mutations and genomic instability that can increase K-RAS mutation and expression $(28,29)$. Although exposure to secondary biliary acids can induce DNA damage and secondary apoptosis, this induced apoptosis may have a beneficial effect in the protection from carcinogenesis through the selection of cells with damaged DNA templates $(30,31)$. Eventually, long-term exposure of colonic epithelial cells to biliary acids may also select cells that are resistant to induced apoptosis, and tumors can arise from these apoptosis-resistant epithelial cells (31-33).

Western style diets that are primarily high in fat can increase the levels of primary and secondary bile acids in the intestinal tract, and may explain the association between biliary disease and CRC (34). Several observational and experimental studies found a positive correlation between high-fat diets, low absorbance of primary biliary acids, and fecal excretion and CRC incidence. These studies suggested that high-fat diets promote the secretion of excess primary bile acids, which in turn correlate positively with mucosal markers of proliferation and tumor formation (35-38). Other studies present the role of secondary bile acids and complex processes of microbial biotransformation of the bile acid pool, which in turn alters the composition of the gut microbiome and may trigger tumor formation or progression by bile acid-induced dysbiosis $(39,40)$. Despite the fact that these studies depict the negative impact of bile acids and their impact of the intestinal microbiome, one research study promoted the anti-inflammatory benefits of ursodeoxycholic acid in alleviating and even preventing chronic intestinal inflammation. Further research is still necessary to completely understand the impact of primary and secondary biliary acids and their impact on the intestinal microbiome and large bowel tumorigenesis $(32,41)$.

An important topic is the effect of cholecystectomy on the risk of CRC. After cholecystectomy, there is continuous emission of bile in the duodenum, causing a prolonged exposure of the small and large bowel mucosa to a large amount of secondary biliary acids $(34,42)$. The carcinogenic mechanism in gallstone disease and a history of cholecystectomy seems to be due to repeated exposure to high concentrations of biliary acids that, in a healthy gallbladder, would normally be concentrated and rhythmically used in digestion $(27,43)$. At the same time, gallbladder disease associated with cholecystectomy can contribute to the alteration of the gastrointestinal microbiome.
A previous study showed that in patients who underwent cholecystectomy for cholelithiasis, analysis of the microbiome revealed bacterial alterations after cholecystectomy, and bacterial dysbiosis was likely associated with the onset of carcinogenesis (44).

The results of the studies that focus on the association between gallbladder disease and CRC seem to be inconsistent, and somewhat controversial. A population-based cohort consisting of 62,615 patients who underwent cholecystectomy and had a 23-year follow-up period found no increased risk of CRC after cholecystectomy, but an increased risk of right-sided colon cancer among women 15 years or more after the operation was observed, which was consistent with some earlier reports (45-47). Another population-based cohort study with $>40,000$ patients and a 15-year follow-up period revealed only a borderline significant association between gallstones and cancer of the colon (48). One meta-analyses suggested that cholecystectomy likely increases the prevalence rate of $\mathrm{CRC}$, particularly the risk of right-sided colon cancer (49). Another cohort study that analyzed $>278,460$ surgical patients, with a maximum follow-up period of a 33 years, found that cholecystectomy increases the risk of intestinal cancer and right-sided colon cancer (50).

The present study confirmed that there were significant differences concerning the location of the CRC between groups $(\mathrm{P}=0.001)$. In the $\mathrm{CRC}$ only group, the most common location was the rectum $(39.7 \%)$, followed by localization on the descending and sigmoid colon (26.6\%), ascending colon $(20.7 \%)$ and transverse colon (13\%). In the gallstone and CRC group, the most common location of the tumor was the ascending colon $(47.4 \%)$, followed by localization in the transverse colon (26.3\%), descending and sigmoid colon $(21.1 \%)$, and rectum $(5.3 \%)$. The present study found a positive association between the presence of gallstones and the tumor location in the colon, with gallstone patients having the primary tumor located in the right colon (ascending colon followed by transverse colon). These data are consistent with the results of a meta-analysis of 10 cohort studies (51).

There are a few study limitations that should be considered. Due to the retrospective nature of the present study and the absence of a preoperative evaluation protocol, it is possible that some patients had incomplete diagnoses, so the number of synchronous gallstone and CRC cases may have been even higher. Despite the limitation presented by the lower number of patients included, the study was able to observe a right shift in tumor location, consistent with the results of previous publications $(52,53)$.

In conclusion, the present study found that in patients with gallstones, age and thyroid conditions were significantly associated with CRC. For patients with comorbid diagnoses of gallstones and CRC, there was a significant increase in right-sided colon cancer. Further research is still necessary to accurately identify and confirm these findings.

\section{Acknowledgements}

The authors would like to thank Dr Frank Ryan (HonorHealth JC Lincoln Medical Center, Phoenix, AZ, USA) and Dr Anca Bailey (Portland, OR, USA) for their assistance with reviewing the English language of the original manuscript. 


\section{Funding}

No funding was received.

\section{Availability of data and materials}

The datasets used and/or analyzed during the current study are available from the corresponding author on reasonable request.

\section{Authors' contributions}

NOZ, ECZ and RC conceived and designed the current study. NOZ, ECZ, AI and RC provided administrative support. NOZ, ECZ, ID, AC, NS, AI and RC searched the literature for pertinent data and findings. NOZ, ECZ, ID, AC and NS collected and collated the data. NOZ, AC and NS performed the statistical analysis. NOZ, ECZ, ID, AI and RC analyzed and interpreted the data. NOZ, ECZ and RC confirm the authenticity of all the raw data. All authors wrote the manuscript, and all authors read and approved the final manuscript for publication.

\section{Ethics approval and consent to participate}

The study complied with the Declaration of Helsinki and was approved by the Institutional Review Board of the Emergency University Hospital of Bucharest (Romania) (approval no. 41471/15.07.2021). Written informed consent was obtained from all patients.

\section{Patient consent for publication}

The patients consented to the publication of their data in the present study.

\section{Competing interests}

The authors declare that they have no competing interests.

\section{References}

1. Sung H, Ferlay J, Siegel RL, Laversanne M, Soerjomataram I, Jemal A and Bray F: Global cancer statistics 2020: GLOBOCAN estimates of incidence and mortality worldwide for 36 cancers in 185 countries. CA Cancer J Clin 71: 209-249, 2021.

2. Buechler SA, Stephens MT, Hummon AB, Ludwig K, Cannon E, Carter TC, Resnick J, Gökmen-Polar Y and Badve SS: ColoType: A forty gene signature for consensus molecular subtyping of colorectal cancer tumors using whole-genome assay or targeted RNA-sequencing. Sci Rep 10: 12123, 2020.

3. Guinney J, Dienstmann R, Wang X, de Reyniès A, Schlicker A, Soneson C, Marisa L, Roepman P, Nyamundanda G, Angelino P, et al: The consensus molecular subtypes of colorectal cancer. Nat Med 21: 1350-1356, 2015.

4. Sirinukunwattana K, Domingo E, Richman SD, Redmond KL, Blake A, Verrill C, Leedham SJ, Chatzipli A, Hardy C, Whalley CM, et al: Image-based consensus molecular subtype (imCMS) classification of colorectal cancer using deep learning. Gut 70: 544-554, 2021.

5. Japanese Society for Cancer of the Colon and Rectum: Japanese classification of colorectal, appendiceal, and anal carcinoma: The $3 \mathrm{~d}$ english edition (secondary publication). J Anus Rectum Colon 3: 175-195, 2019.

6. Pei JP, Zhang CD, Fu X, Ba Y, Yue S, Zhao ZM and Dai DQ: A novel TNM classification for colorectal cancers based on the metro-ticket paradigm. J Cancer 12: 3299-3306, 2021.
7. Tebala GD, Hameed W, Di Saverio S, Gallo G and Bond-Smith G: Proposal and validation of a new classification of surgical outcomes after colorectal resections within an enhanced recovery programme. Surg Res Pract 2021: 8864555, 2021.

8. Shabanzadeh DM, Sørensen LT and Jørgensen T: Gallstone disease and mortality: A cohort study. Int J Public Health 62: 353-360, 2017.

9. Manzia TM, Quaranta C, Filingeri V, Toti L, Anselmo A, Tariciotti L, De Carolis G, Cacciola R, Di Lorenzo N, Sorge R, et al: Feasibility and cost effectiveness of ambulatory laparoscopic cholecystectomy. A retrospective cohort study. Ann Med Surg (Lond) 55: 56-61, 2020.

10. Sutherland JM, Mok J, Liu G, Karimuddin A and Crump T: A cost-utility study of laparoscopic cholecystectomy for the treatment of symptomatic gallstones. J Gastrointest Surg 24: 1314-1319, 2020

11. Teixeira UF, Goldoni MB, Machry MC, Ceccon PN, Fontes PR and Waechter FL: AMBULATORY LAPAROSCOPIC CHOLECYSTECTOMY IS SAFE AND COST-EFFECTIVE: A Brazilian single center experience. Arq Gastroenterol 53: 103-107, 2016.

12. Bundgaard NS, Bohm A, Hansted AK and Skovsen AP: Early laparoscopic cholecystectomy for acute cholecystitis is safe regardless of timing. Langenbecks Arch Surg 406: 2367-2373, 2021.

13. Chan KS, Mohan R, Low JK, Junnarkar SP, Huey CWT and Shelat VG: Elderly patients ( $\geq 80$ years) with acute calculous cholangitis have similar outcomes as non-elderly patients ( $<80$ years): Propensity score-matched analysis. World J Hepatol 13: 456-471, 2021.

14. Lin YN, Wu YT, Fu CY, Liao CH, Cheng CT, Wang SY, Lin BC, Hsu YP, Kang SC, Liu EH, et al: Evaluating the advantages of treating acute cholecystitis by following the Tokyo guidelines 2018 (TG18): A study emphasizing clinical outcomes and medical expenditures. Surg Endosc 35: 6623-6632, 2020.

15. Wakabayashi G, Iwashita Y, Hibi T, Takada T, Strasberg SM, Asbun HJ, Endo I, Umezawa A, Asai K, Suzuki K, et al: Tokyo guidelines 2018: surgical management of acute cholecystitis: Safe steps in laparoscopic cholecystectomy for acute cholecystitis (with videos). J Hepatobiliary Pancreat Sci 25: 73-86, 2018.

16. Gál I, Szívós J, Jaberansari MT and Szabó Z: Laparoscopic cholecystectomy. Risk of missed pathology of other organs. Surg Endosc 12: 825-827, 1998.

17. Icoz G, Makay O, Dayangac M, Zeytunlu M, Kilic M and Korkut M: Missed intra-abdominal malignancies after laparoscopic cholecystectomy. Ann Saudi Med 25: 172-173, 2005.

18. Ishida H, Ohsawa T, Murata N, Fujioka M and Hashimoto D: Risk of missing colorectal cancer during laparoscopic cholecystectomy. Surg Today 32: 392-396, 2002.

19. Wysocki A, Lejman W and Bobrzynski A: Abdominal malignancies missed during laparoscopic cholecystectomy. Surg Endosc 15: 959-961, 2001.

20. Malouf AJ, Murray AW and MacGregor AB: Major intraabdominal pathology missed at laparoscopic cholecystectomy. Br J Surg 87: 1434-1435, 2000.

21. Radmard AR, Merat S, Kooraki S, Ashraf M, Keshtkar A, Sharafkhah M, Jafari E, Malekzadeh R and Poustchi H: Gallstone disease and obesity: A population-based study on abdominal fat distribution and gender differences. Ann Hepatol 14: 702-709, 2015.

22. Sun H, Tang H, Jiang S, Zeng L, Chen EQ, Zhou TY and Wang YJ: Gender and metabolic differences of gallstone diseases. World J Gastroenterol 15: 1886-1891, 2009.

23. Bonfrate L, Wang DQ, Garruti G and Portincasa P: Obesity and the risk and prognosis of gallstone disease and pancreatitis. Best Pract Res Clin Gastroenterol 28: 623-635, 2014.

24. Wang Y, Yu X, Zhao QZ, Zheng S, Qing WJ, Miao CD and Sanjay J: Thyroid dysfunction, either hyper or hypothyroidism, promotes gallstone formation by different mechanisms. J Zhejiang Univ Sci B 17: 515-525, 2016.

25. Hofmann AF: The continuing importance of bile acids in liver and intestinal disease. Arch Intern Med 159: 2647-2658, 1999.

26. Ridlon JM, Kang DJ and Hylemon PB: Bile salt biotransformations by human intestinal bacteria. J Lipid Res 47: 241-259, 2006.

27. Bernstein H, Bernstein C, Payne CM and Dvorak K: Bile acids as endogenous etiologic agents in gastrointestinal cancer. World J Gastroenterol 15: 3329-3340, 2009.

28. Payne CM, Bernstein C, Dvorak K and Bernstein H: Hydrophobic bile acids, genomic instability, Darwinian selection, and colon carcinogenesis. Clin Exp Gastroenterol 1: 19-47, 2008. 
29. Narahara H, Tatsuta M, Iishi H, Baba M, Uedo N, Sakai N, Yano H and Ishiguro S: K-ras point mutation is associated with enhancement by deoxycholic acid of colon carcinogenesis induced by azoxymethane, but not with its attenuation by all-trans-retinoic acid. Int J Cancer 88: 157-161, 2000.

30. Scott DW, Mutamba S, Hopkins RG and Loo G: Increased GADD gene expression in human colon epithelial cells exposed to deoxycholate. J Cell Physiol 202: 295-303, 2005.

31. Payne CM, Weber C, Crowley-Skillicorn C, Dvorak K, Bernstein H, Bernstein C, Holubec H, Dvorakova B and Garewal H: Deoxycholate induces mitochondrial oxidative stress and activates NF-kappaB through multiple mechanisms in HCT-116 colon epithelial cells. Carcinogenesis 28: 215-222, 2007.

32. Badvie S, Hanna-Morris A, Andreyev HJ, Cohen P, Saini S and Allen-Mersh TG: A 'field change' of inhibited apoptosis occurs in colorectal mucosa adjacent to colorectal adenocarcinoma. J Clin Pathol 59: 942-946, 2006.

33. Di Ciaula A, Wang DQ, Molina-Molina E, Lunardi Baccetto R, Calamita G, Palmieri VO and Portincasa P: Bile acids and cancer: Direct and environmental-dependent effects. Ann Hepatol 16 (Suppl 1: s3-105): S87-S105, 2017.

34. Saracut C, Molnar C, Russu C, Todoran N, Vlase L, Turdean S, Voidazan S and Copotoiu C: Secondary bile acids effects in colon pathology. Experimental mice study. Acta Cir Bras 30: 624-631, 2015.

35. Schulz MD, Atay C, Heringer J, Romrig FK, Schwitalla S, Aydin B, Ziegler PK, Varga J, Reindl W, Pommerenke C, et al: High-fat-diet-mediated dysbiosis promotes intestinal carcinogenesis independently of obesity. Nature 514: 508-512, 2014

36. Islam KB, Fukiya $S$, Hagio M, Fujii N, Ishizuka S, Ooka T, Ogura Y, Hayashi T and Yokota A: Bile acid is a host factor that regulates the composition of the cecal microbiota in rats. Gastroenterology 141: 1773-1781,2011.

37. Higashimura Y, Naito Y, Takagi T, Uchiyama K, Mizushima K, Ushiroda C, Ohnogi H, Kudo Y, Yasui M, Inui S, et al: Protective effect of agaro-oligosaccharides on gut dysbiosis and colon tumorigenesis in high-fat diet-fed mice. Am J Physiol Gastrointest Liver Physiol 310: G367-G375, 2016.

38. Donohoe DR, Holley D, Collins LB, Montgomery SA, Whitmore AC, Hillhouse A, Curry KP, Renner SW, Greenwalt A, Ryan EP, et al: A gnotobiotic mouse model demonstrates that dietary fiber protects against colorectal tumorigenesis in a microbiota- and butyrate-dependent manner. Cancer Discov 4 $1387-1397,2014$

39. Ocvirk S and O'Keefe SJ: Influence of bile acids on colorectal cancer risk: Potential mechanisms mediated by diet-gut microbiota interactions. Curr Nutr Rep 6: 315-322, 2017.

40. O'Keefe SJ: Diet, microorganisms and their metabolites, and colon cancer. Nat Rev Gastroenterol Hepatol 13: 691-706, 2016.
41. Ward JB, Lajczak NK, Kelly OB, O'Dwyer AM, Giddam AK, Gabhann JN, Franco P, Tambuwala MM, Jefferies CA, Keely S, et al: Ursodeoxycholic acid and lithocholic acid exert anti-inflammatory actions in the colon. Am J Physiol Gastrointest Liver Physiol 312: G550-G558, 2017.

42. Chen YK, Yeh JH, Lin CL, Peng CL, Sung FC, Hwang IM and Kao $\mathrm{CH}$ : Cancer risk in patients with cholelithiasis and after cholecystectomy: A nationwide cohort study. J Gastroenterol 49: 923-931, 2014.

43. Yoon WJ, Kim HN, Park E, Ryu S, Chang Y, Shin H, Kim HL and Yi SY: The impact of cholecystectomy on the gut microbiota: A case-control study. J Clin Med 8: 79, 2019.

44. Ren X, Xu J, Zhang Y, Chen G, Zhang Y, Huang Q and Liu Y: Bacterial alterations in post-cholecystectomy patients are associated with colorectal cancer. Front Oncol 10: 1418, 2020.

45. Ekbom A, Yuen J, Adami HO, McLaughlin JK, Chow WH, Persson I and Fraumeni JF Jr: Cholecystectomy and colorectal cancer. Gastroenterology 105: 142-147, 1993.

46. Alley PG and Lee SP: The increased risk of proximal colonic cancer after cholecystectomy. Dis Colon Rectum 26: 522-524, 1983.

47. Vernick LJ and Kuller LH: Cholecystectomy and right-sided colon cancer: An epidemiological study. Lancet 2: 381-383, 1981.

48. Johansen C, Chow WH, Jorgensen T, Mellemkjaer L, Engholm G and Olsen JH: Risk of colorectal cancer and other cancers in patients with gall stones. Gut 39: 439-443, 1996.

49. Zhang Y, Liu H, Li L, Ai M, Gong Z, He Y, Dong Y, Xu S, Wang J, Jin B, et al: Cholecystectomy can increase the risk of colorectal cancer: A meta-analysis of 10 cohort studies. PLoS One 12: e0181852, 2017.

50. Lagergren J, Ye W and Ekbom A: Intestinal cancer after cholecystectomy: Is bile involved in carcinogenesis? Gastroenterology 121: 542-547, 2001.

51. Zhang Y, Liu H, Li L, Ai M, Gong Z, He Y, Dong Y, Xu S, Wang J, Jin B, et al: Correction: Cholecystectomy can increase the risk of colorectal cancer: A meta-analysis of 10 cohort studies. PLoS One 13: e0191587, 2018

52. Shabanzadeh DM, Sørensen LT and Jørgensen T: Association between screen-detected gallstone disease and cancer in a cohort study. Gastroenterology 152: 1965-1974.e1, 2017.

53. Gosavi S, Mishra RR and Kumar VP: Study on the relation between colorectal cancer and gall bladder disease. J Clin Diagn Res 11: OC25-OC27, 2017.

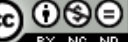

This work is licensed under a Creative Commons Attribution-NonCommercial-NoDerivatives 4.0 International (CC BY-NC-ND 4.0) License. 